\title{
Stress-strain behaviour of Toyoura sand in undrained triaxial compression
}

\author{
Katarzyna Dołżyk-Szypcio ${ }^{1, *}$ \\ ${ }^{1}$ Bialystok University of Technology, Faculty of Civil and Environmental Engineering, Wiejska 45E, 15-351 Bialystok, Poland
}

\begin{abstract}
The stress-plastic dilatancy relationship for Toyoura sand sheared under undrained triaxial conditions was analysed by use of Frictional State Theory. Under undrained conditions, plastic strain increments are counterbalanced by elastic strain increments. The linear stress ratio-plastic dilatancy relationships at different stages of sand shear were obtained by assuming that Poisson's ratio is a function of shear strain. Contrary to a drained condition, natural state parameter values are not special for characteristic points of sand behaviour under undrained conditions.
\end{abstract}

\section{Introduction}

Stress-dilatancy relationships for sands were widely investigated under drained conditions [e.g., 1-4]. For undrained conditions, there were no volume changes during shear. Therefore, only interactions between elastic and plastic strain increments may be analysed. A general stress-plastic dilatancy relationship for soils was developed by Szypcio [5] on the basis of Frictional State Theory. Frictional State Theory makes it possible to define the natural state parameter [6] as an extension of the state parameter defined by Been and Jeffries [7]. At failure and post-failure shearing of sand under drained triaxial compression, the natural state parameter value equals almost zero. This may be useful for sand modelling in the future.

In this paper, some undrained triaxial tests of Toyoura sand conducted by Verdugo [8] are analysed and stress-plastic dilatancy relationships are calculated. In this work, it is assumed, like in many sand models, that the elastic shear modulus is a function of void ratio and stress level. The linear stress-plastic dilatancy relationship is obtained by assuming that Poisson's ratio is a function of strain. It will be shown that the stressplastic dilatancy relationship is characteristic for different stages of shear.

\section{Stress-plastic dilatancy relationship}

The stress-plastic dilatancy relationship has a linear form [6]:

$$
\eta=Q-A D^{p}
$$

where

$$
\eta=q / p^{\prime}
$$

$$
\begin{gathered}
Q=M^{\mathrm{o}}-\alpha A^{\mathrm{o}} \\
A=\beta A^{\mathrm{o}} \\
D^{p}=\delta \varepsilon_{\mathrm{v}}^{p} / \delta \varepsilon_{q}^{p}
\end{gathered}
$$

For triaxial compression [9],

$$
\begin{gathered}
q=\sigma_{1}^{\prime}-\sigma_{3}^{\prime} \\
p^{\prime}=\left(\sigma_{1}^{\prime}+2 \sigma_{3}^{\prime}\right) / 3 \\
\delta \varepsilon_{\mathrm{v}}^{p}=\delta \varepsilon_{1}^{p}+2 \delta \varepsilon_{3}^{p} \\
\delta \varepsilon_{q}^{p}=2\left(\delta \varepsilon_{1}^{p}-\delta \varepsilon_{3}^{p}\right) / 3
\end{gathered}
$$

where $\sigma_{1}^{\prime}, \sigma_{3}^{\prime}, \delta \varepsilon_{1}^{p}$, and $\delta \varepsilon_{3}^{p}$ are maximum and minimum effective major and minor stresses and plastic strain increments, respectively.

For undrained triaxial compression [5],

$$
\begin{gathered}
M^{\mathrm{o}}=M_{c}^{\mathrm{o}}=\left(6 \sin \Phi^{\mathrm{o}}\right) /\left(3-\sin \Phi^{\mathrm{o}}\right) \\
A^{\mathrm{o}}=A_{c}^{\mathrm{o}}=1+\left(2 M_{c}^{\mathrm{o}} / 3\right)
\end{gathered}
$$

where $\Phi^{\circ}$ is the angle of friction at the critical frictional state and $\alpha$ and $\beta$ are Frictional State Theory soil parameters [6] (Fig.1).

The plastic parts of the volumetric and shear strain increment are

$$
\begin{aligned}
& \delta \varepsilon_{\mathrm{v}}^{p}=\delta \varepsilon_{\mathrm{v}}-\delta \varepsilon_{\mathrm{v}}^{e} \\
& \delta \varepsilon_{q}^{p}=\delta \varepsilon_{q}-\delta \varepsilon_{q}^{e}
\end{aligned}
$$

where

\footnotetext{
* Corresponding author: k.dolzyk@pb.edu.pl
} 


$$
\begin{gathered}
\delta \varepsilon_{\mathrm{v}}^{e}=\delta p^{\prime} / K \\
\delta \varepsilon_{q}^{e}=\delta q / 3 G \\
G=G_{\mathrm{o}}^{*} p_{a}\left[(2.97-e)^{2} /(1+e)\right]\left(p^{\prime} / p_{a}\right)^{0.5} \\
K=(2 / 3)[(1+v) /(1-2 v)] G
\end{gathered}
$$

where $v$ is Poisson's ratio [5], e is the void ratio, $\mathrm{G}_{\mathrm{o}}{ }^{*}$ is a sand constant, and $\mathrm{p}_{\mathrm{a}}$ is atmospheric pressure $(=101 \mathrm{kPa})$.

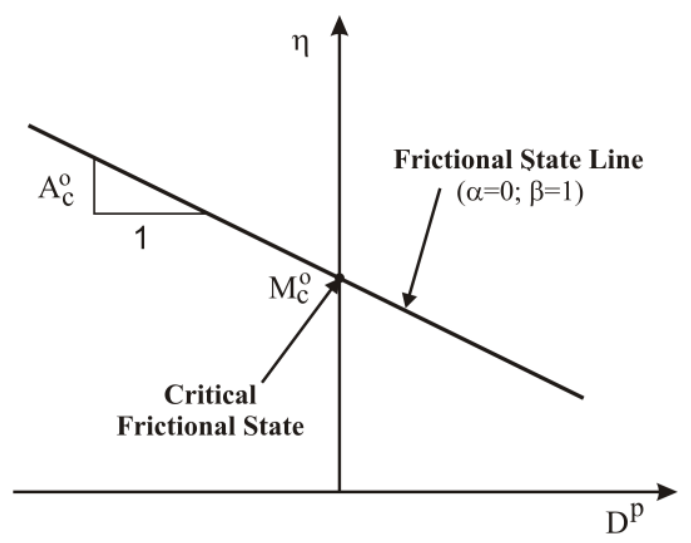

Fig. 1. Frictional state line in $\eta-D^{P}$ plane for triaxial compression.

For undrained triaxial compression $\delta \varepsilon_{v}=0$ and $\delta \varepsilon_{\mathrm{q}}=\delta \varepsilon_{1}$, a frictional state is a state at which $\alpha=0$ and $\beta=1$ [5] and the frictional state line (FSL) in plane $\eta-D^{P}$ crosses the vertical axis $\eta$ at $M_{c}^{o}$ and slope $A_{c}^{o}$ to the horizontal axis (Fig.1).

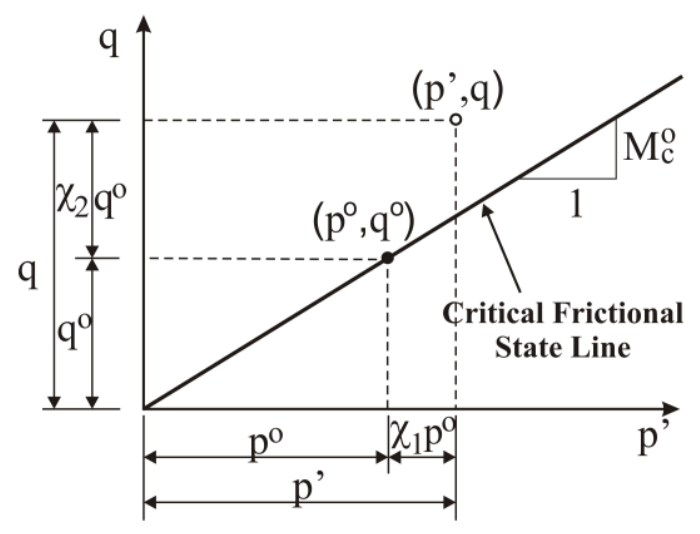

Fig. 2. Current and critical frictional state stresses for triaxial compression.

The current stresses (q, p') are functions of critical frictional stresses $\left(\alpha=0, \beta=1, D^{P}=0, q^{\circ}, p^{\circ}\right)[5,9]$ and natural dilatancy (Fig.2).

$$
\begin{gathered}
p^{\prime}=\left(1+\chi_{1}\right) p^{\mathrm{o}} \\
q=\left(1+\chi_{2}\right) q^{\mathrm{o}} \\
D^{p n}=\alpha+\beta D^{p}
\end{gathered}
$$

where for undrained triaxial conditions,

$$
\begin{gathered}
\chi_{1}=2 D^{p n} /\left(3-2 D^{p n}\right) \\
\chi_{2}=-\left\{3 D^{p n} /\left[M_{c}^{\mathrm{o}}\left(3-2 D^{p n}\right)\right]\right\}
\end{gathered}
$$

\section{Natural state parameter}

The natural state parameter $\Psi^{\circ}$ was defined by DołżykSzypcio [6] as an extension of the state parameter defined by Been and Jefferies [7]. The state parameter is the difference between the current void ratio and critical state void ratio for the same mean stress ( $\left.p^{\prime}\right)$,

$$
\Psi=e-e_{c}
$$

For Toyoura sand,

$$
e_{c}=e_{\Gamma}-\lambda_{c}\left(p^{\prime} / p_{a}\right)^{\xi}
$$

where $e_{\Gamma}=0.934, \lambda_{c}=0.019$, and $\xi=0.7[6,10]$.

The natural state parameter, denoted as $\Psi^{\circ}$, is a sum of two components,

$$
\Psi^{\mathrm{o}}=\Psi_{e}^{\mathrm{o}}+\Psi_{\eta}^{\mathrm{o}}
$$

where

$$
\Psi_{e}^{o}=e-e_{c}^{o}
$$

and

$$
e_{c}^{\mathrm{o}}=e_{\Gamma}^{\mathrm{o}}-\lambda_{c}^{o}\left(p^{\mathrm{o}} / p_{a}\right)^{\xi^{o}}
$$

where $\Psi_{\eta}{ }^{\circ}$ represents the normalized difference between current stress ratio $\eta$ and critical frictional state ratio $\mathrm{M}^{\circ}$ (Fig. 3).
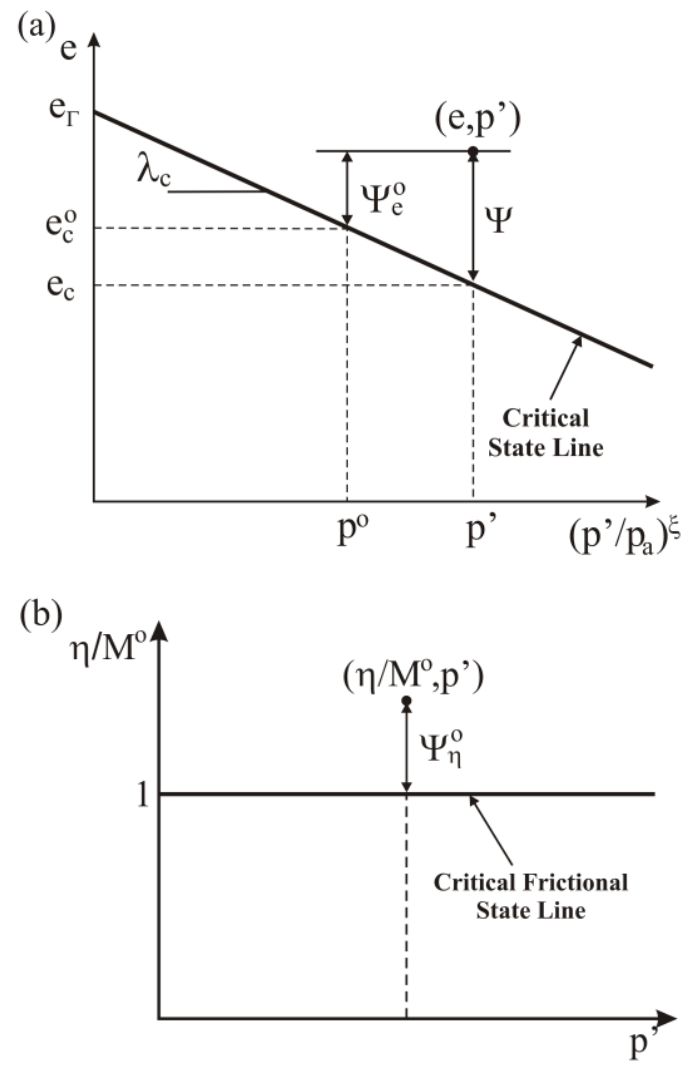

Fig. 3. Natural state parameter components: a) $\Psi_{\mathrm{e}}{ }^{\circ}$, b) $\Psi_{\eta}{ }^{\circ}$. 
For many sands, $\Phi^{\circ}=\Phi_{\mathrm{cu}}$ [9]. Therefore, the critical frictional stresses equal the critical stresses $\left(\mathrm{p}^{\circ}=\mathrm{p}_{\mathrm{c}}\right.$, $\left.\mathrm{q}^{\circ}=\mathrm{q}_{\mathrm{c}}\right)$ and it is assumed that $e_{\Gamma}^{\mathrm{o}}=e_{\Gamma}, \lambda_{c}^{\mathrm{o}}=\lambda_{c}$, and $\xi^{\circ}=\xi$. For triaxial compression, $\mathrm{M}^{\circ}=\mathrm{M}_{\mathrm{c}}{ }^{\circ}$. Therefore,

$$
\Psi_{\eta}^{\mathrm{o}}=\left(\eta-M_{c}^{\mathrm{o}}\right) / M_{c}^{\mathrm{o}}=\left(\chi_{2}-\chi_{1}\right) /\left(1+\chi_{1}\right)
$$

For drained triaxial compression at failure and postfailure states, $\Psi^{\circ}=0$. In this work, $\Psi^{\circ}$ will be computed for undrained triaxial compression tests on Toyoura sand conducted by Verdugo [8].

\section{Analysis and results}

This work analysed only experimental data from three undrained triaxial tests of Toyoura sand conducted by Verdugo [8]. Samples at different initial void ratios $\mathrm{e}_{\mathrm{o}}$ (0.861, 0.883, and 0.910) were isotropically consolidated $\left(\mathrm{p}^{\prime}{ }_{\mathrm{o}}=490 \mathrm{kPa}\right)$ and sheared under undrained triaxial conditions. The relationships between $q-\gamma\left(\gamma=\varepsilon_{1}-\varepsilon_{3}\right)$ and q-p' obtained from these tests were sectionally approximated by high-degree polynomials. Some experimental points are shown in Fig. 4.
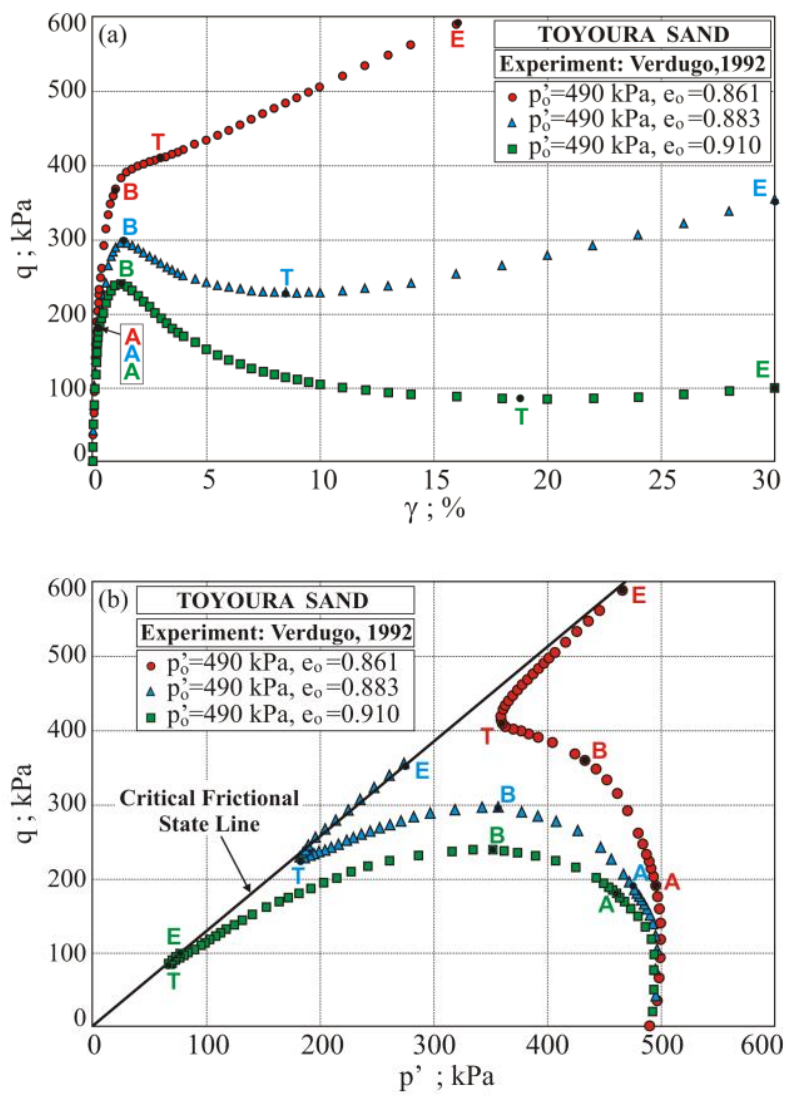

Fig. 4. Experimental relationships: a) $q-\gamma$, b) $q-p$ '.

The elastic shear modulus of Toyoura sand for this stress level was calculated from equation (16) with $\mathrm{G}_{0}{ }^{*}=120$. Poisson's ratio is a function of shear strain (Fig.5).

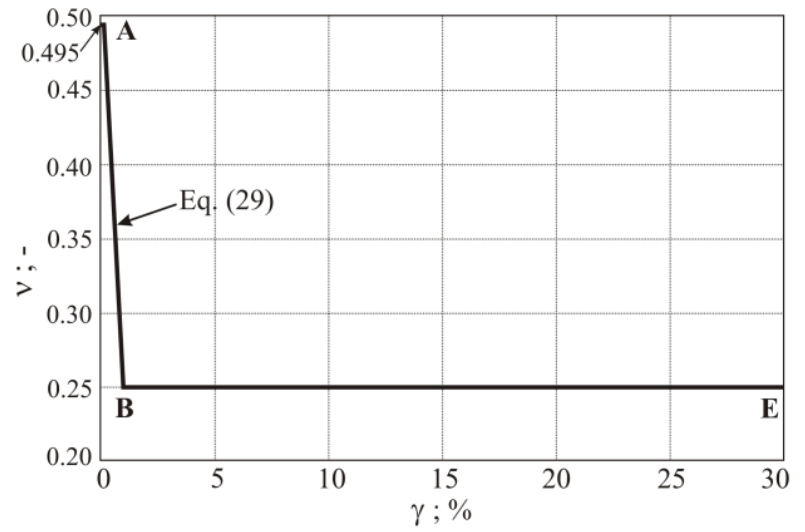

Fig. 5. Poisson's ratio for undrained triaxial compression test of Toyoura sand.

$$
v= \begin{cases}0.495 & \text { for } \gamma<0.2 \% \\ 0.495-0.302(\gamma-0.2) & \text { for } 0.2 \% \leq \gamma<1 \% \\ 0.25 & \text { for } \gamma \geq 1 \%\end{cases}
$$

The $\eta-D^{P}$ relationships obtained from calculations are shown in Fig. 6. The characteristic points of this relationships are denoted as $\mathrm{A}, \mathrm{B}, \mathrm{T}$, and E. Points A represent $\eta \approx 0.4$ for all tests. At the initial stage of shearing, before $\eta$ represented by points $A, v=0.495$. At further shear, values of $v$ drop and at points B reach the smallest value $v=0.25$, similar to the value of $v$ for drained conditions. Points B represent the maximum value of shear stress $q$ for type $B$ (contractive then dilative) behaviour. Points $\mathrm{B}$ are not characteristic in the $\mathrm{q}-\gamma$ plane for type $C$ (dilative) behaviour [11]. Points $T$ represent the transformation state. For type B behaviour, these points represent the minimum value of $\mathrm{q}$ and no increment of $p^{\prime}$ values $\left(D^{P}=0\right)$. For type $C$ behaviour, these points represents the minimum value of $\mathrm{p}^{\prime}$ and no increment of mean stress $\left(\delta p^{\prime}=D^{P}=0\right)$. Points E represent the state at which the experiments were interrupted at $\eta \approx \mathrm{M}_{\mathrm{c}}{ }^{\circ}=1.265\left(\Phi^{\circ}=31.5^{\circ}\right)$. The characteristic points $\mathrm{A}$, $\mathrm{B}, \mathrm{T}$, and $\mathrm{E}$ are also marked in Fig. 4. The critical frictional state angle $\Phi^{\circ}=31.5^{\circ}$ was assumed for calculation of stress-plastic dilatancy behaviour of Toyoura sand [5-6, 9]. For all stages of shearing, the approximated straight lines defined by equation (1) were established and parameters $\alpha$ and $\beta$ were calculated; the results are shown in Fig.6. Parameters $\alpha$ and $\beta$ cannot be calculated for the initial stage of shearing $(\eta<0.4)$. In Figs. 4 and 6 , the FSL $\left(\alpha=0, \beta=1\right.$, and $\left.Q=M_{c}{ }^{\circ}=1.265\right)$ is also shown. 

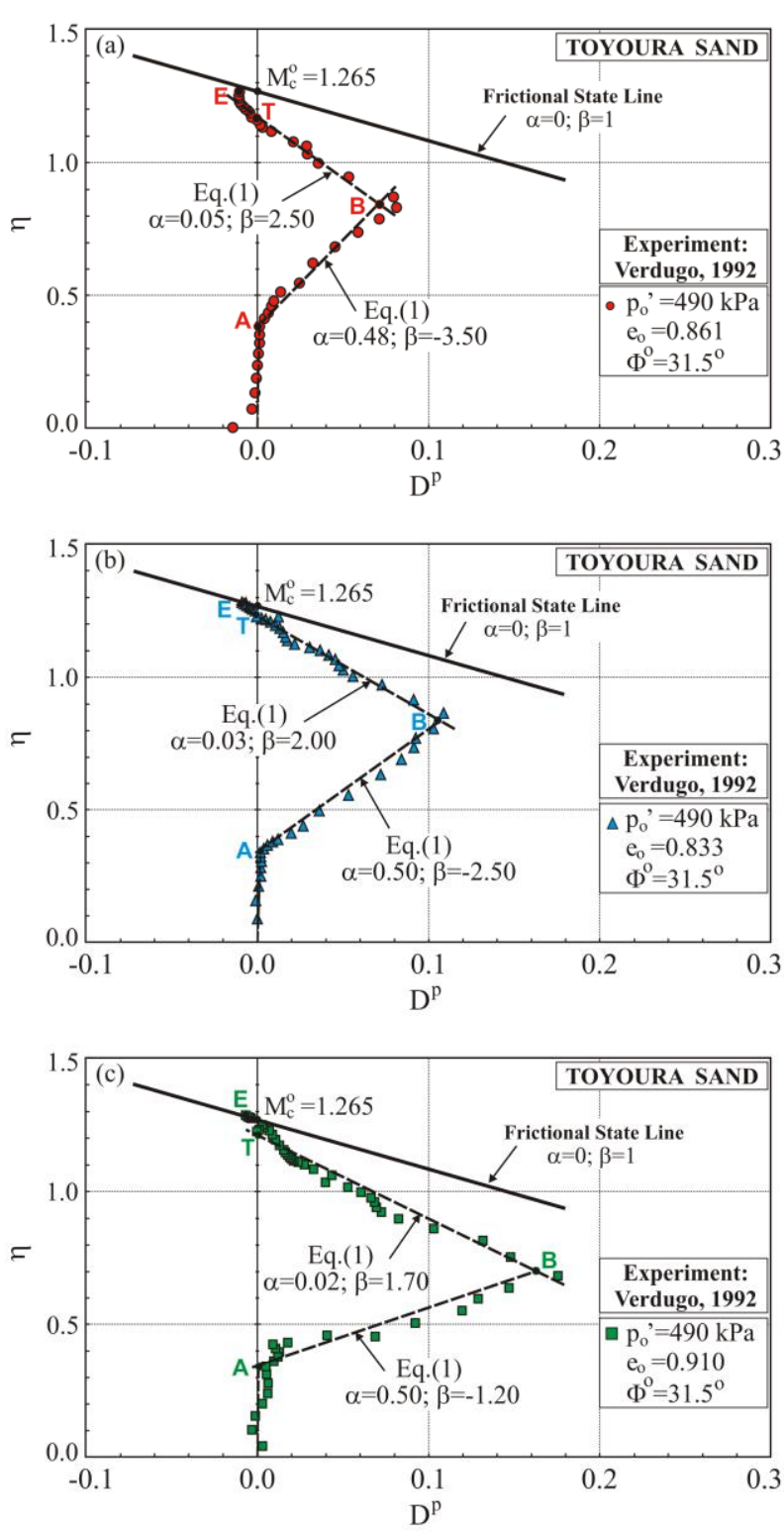

Fig. 6. Stress ratio-plastic dilatancy for tests: a) $\left.\mathrm{e}_{0}=0.861, \mathrm{~b}\right) \mathrm{e}_{\mathrm{o}}$ $=0.883, \mathrm{c}) \mathrm{e}_{\mathrm{o}}=0.910$.

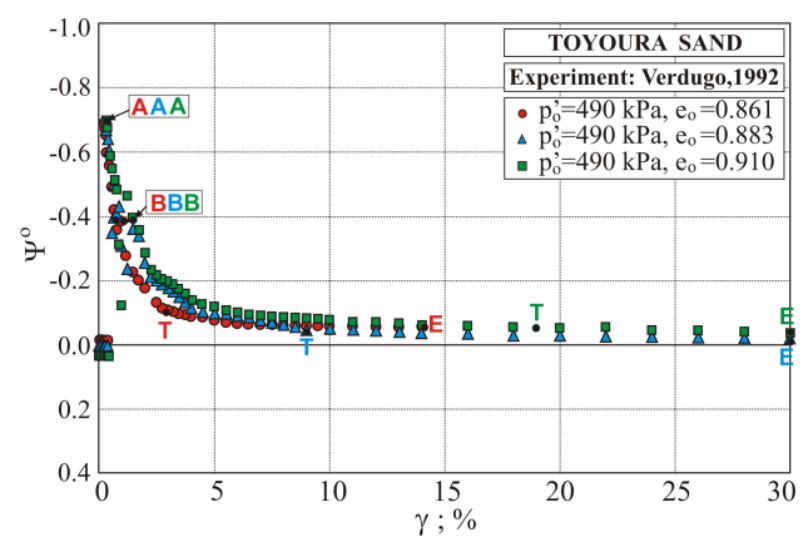

Fig. 7. Natural state parameter for Toyoura sand.

The natural state parameter was calculated and is shown in Fig. 7. Generally, values of the natural state parameter are negative for the analysed sand. Absolute values of the natural state parameter drop during shear but do not reach zero, even at large shear strains.

\section{Conclusions}

The stress-plastic dilatancy relationship for undrained triaxial compression may be obtained by use of Frictional State Theory. The plastic strain increments are counterbalanced by elastic strain increments. The linear relationship at different stages of shearing are obtained by assuming the dependence of the elastic shear modulus on stress level and void ratio, similarly to drained conditions, and assuming Poisson's ratio is function of shear strain. Contrary to drained conditions, the values of the natural state parameters are not special at characteristic points of sand behaviour under undrained conditions. The stress-plastic dilatancy relationship is very sensitive to the elastic parameters of sand $(G, v)$ and more research is needed in the future to explain it.

\section{References}

1. D. H. Cornforth. Géotechnique 14, 1 (1964)

2. X. - S. Li, Y. F. Dafalias, Z. - L. Wang. Can. Geotech. J. 36, 599-619 (1999)

3. H. Matsuoka. Soils Found. 14, 1 (1974)

4. P. W. Rowe. Géotechnique 19, 1 (1969)

5. Z. Szypcio. Studia Geotechnica et Mechanica 38, 51-57 (2016)

6. K. Dołżyk-Szypcio. Proceedings of China - Europe Conference on Geotechnical Engineering, SSGG, 140-143 (2018)

7. K. Been, M. Jefferies. Géotechnique 35, 2 (1985)

8. R. Verdugo. PhD dissertation. University of Tokyo (1992)

9. Z. Szypcio. Studia Geotechnica et Mechanica 38, 59-65 (2016)

10. Y. P. Yao, H. Yamamoto, N. D. Wang. Soils Found. 48, 4 (2008)

11. S. M. Olsen, B. B. Mattson. Can. Geotech. J. 45, 574-587 (2008) 